\title{
Constancy of relative body weight in children
}

\author{
EZRA SOHAR, EITHAN SCAPA, and MORDECHAI RAVID \\ From the Heller Institute of Medical Research, Tel-Aviv University Medical School, Tel-Hashomer, Israel
}

\begin{abstract}
Sohar, E., Scapa, E., and Ravid, M. (1973). Archives of Disease in Childhood, 48, 389. Constancy of relative body weight in children. The height and weight records of 404 schoolchildren at age 6 to 7 and at age 13 to 14 were analysed. Relative weight (i.e. \% of ideal weight for height) of a child tended to change little over this period of 7 to 8 years of rapid growth. The correlation coefficient of relative weight for the group at the two ages was 0.81 . In only $6 \%$ of the children did relative weight change more than $20 \%$ in either direction.

This stability of relative body weight, despite the variations in environmental factors during school years, emphasizes the dominant role of genetic factors in the monitoring of body weight.
\end{abstract}

Although the importance of genetic factors in the maintenance of body weight is generally accepted, the magnitude of environmental influences is under debate (Mayer, 1965; Bruch and Touraine, 1940; Mendelson, 1966; Mayer, 1966). Childhood is marked by great and rapid environmental changes: height, absolute weight, hormonal balance, eating habits, physical and social activity, etc., all change greatly during the school years. Observations on changes of relative weight in childhood should therefore provide some insight into the importance of environmental factors on the maintenance of body weight. This paper reports a study comparing the height and weight of schoolchildren at age 6 to 7 with that at age 13 to 14, and determining the degree of correlation between the children's relative weight at these two ages.

\section{Subjects and methods}

The school health records of pupils who attended, in 1970, the 8th grade in 12 randomly selected elementary schools in the Tel-Aviv area comprised the material of this study. Recording of height and weight was performed by school nurses on children in their underwear and without shoes.

All children were included if the height and weight records could be obtained for both ages 6 to 7 and 13 to 14 . There were 404 children, 216 boys and 188 girls.

The mean 'ideal' weight for each height was calculated from the centile tables of Stuart and Meredith (1969); relative weight is the percentage of this 'ideal' weight. The records of the children were analysed to determine the degree of correlation between the relative weight

Received 30 August 1972. of each child in the two age groups. The correlation coefficient was computed and linear regression equations calculated for the whole sample, then separately for boys and girls, and for obese and nonobese children. For the calculation of correlation coefficients only, we have chosen arbitrarily $120 \%$ of 'ideal' weight as the limit between obese and nonobese.

\section{Results}

The mean relative weight of the group was $103 \% \pm 12$ SD (boys $102 \pm 13$, girls $104 \pm 12$ ) at age 6 to 7 , and $108 \% \pm 16$ SD (boys $109 \pm 15$, girls $107 \pm 17)$ at age 13 to 14 . The distribution of the children according to relative weight at age 6 to 7 and at 13 to 14 is summarized in Table I

TABLE I

Relative weight of 404 children at ages 6 to 7 and 13 to 14

\begin{tabular}{|c|c|c|c|c|}
\hline \multirow{2}{*}{$\%$ of ideal weight } & \multicolumn{2}{|c|}{ Age 6 to 7} & \multicolumn{2}{|c|}{ Age 13 to 14} \\
\hline & No. & $\%$ & No. & $\%$ \\
\hline $\begin{array}{c}70-90 \\
91-110 \\
111-130 \\
131-150\end{array}$ & $\begin{array}{r}50 \\
255 \\
82 \\
17\end{array}$ & $\begin{array}{r}12 \cdot 5 \\
63 \cdot 0 \\
20 \cdot 5 \\
4 \cdot 0\end{array}$ & $\begin{array}{r}48 \\
218 \\
99 \\
39\end{array}$ & $\begin{array}{r}12 \cdot 0 \\
54 \cdot 5 \\
24 \cdot 0 \\
9 \cdot 5\end{array}$ \\
\hline Total & 404 & $100 \cdot 0$ & 404 & $100 \cdot 0$ \\
\hline
\end{tabular}

and Fig. 1. The percentage of children in each weight class changed little, with a tendency towards increase in relative weight with age. The numbers of slim children ( 70 to $90 \%$ of ideal 


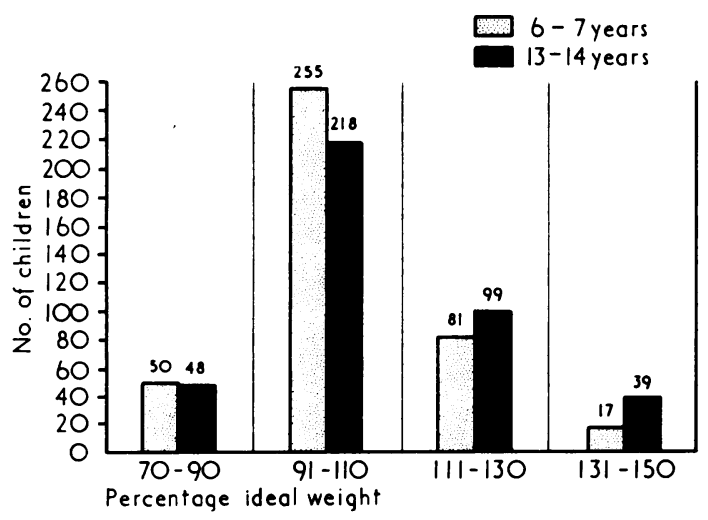

Fig. 1.-Distribution of the 404 children according to weight groups.

weight) remained virtually unchanged. In the groups of 91 to 110 and 111 to $130 \%$ of ideal weight, changes were small. Only the number of obese children (130 to $150 \%$ of ideal weight) increased from 17 at age 6 to 7 , to 39 at age 13 to 14 , that is from $4 \%$ to $9.5 \%$ of the total number of children.

The shift in relative weight that occurred between age 6 to 7 and 13 to 14 is summarized in Table II. $30(60 \%)$ of the 50 children whose relative weight at age 6 to 7 was below $90 \%$ maintained the same relative weight at age 13 to 14 . The other 20 children $(40 \%)$ showed an increase in relative weight, though it still remained below $100 \%$ in 8 . An important increase in relative weight was thus observed in 12 children only. About $80 \%$ of all other children (relative weight 90 to $130 \%$ at age 6 to 7 ) maintained their original relative weight also at age 13 to 14 . Of the $20 \%$ where there was a significant change in relative weight, this increased in 41 children and decreased in 25.

However, the shift from one relative weight group to the next often represented only a small change. Thus, among the 25 children whose relative weight had been 91 to $110 \%$ at age 6 to 7 and increased to 111 to $130 \%$ at age 13 to 14 , only 12 showed an increase of more than $10 \%$. None of the obese children (relative weight higher than $130 \%$ ) showed a significant change in their relative weight.

Fig. 2 shows that an increase in relative weight occured in 63 children and a decrease in relative weight in 25 children. An excessive increase in relative weight of $20 \%$ or more occurred in 22 children only $(5 \%)$ and a decrease of more than $20 \%$ in one child only. At age 13 to 14,138 children showed a relative weight of over $110 \%$ (of ideal weight): 91 of them had had the same relative weight at age 6 to 7, the relative weight of an additional 25 had been over $100 \%$ (Table II). Thus, in only $22(16 \%)$ did the relative weight increase from below $100 \%$ at age 6 to 7 to over $110 \%$ at age 13 to 14 . Of the 218 normal relative

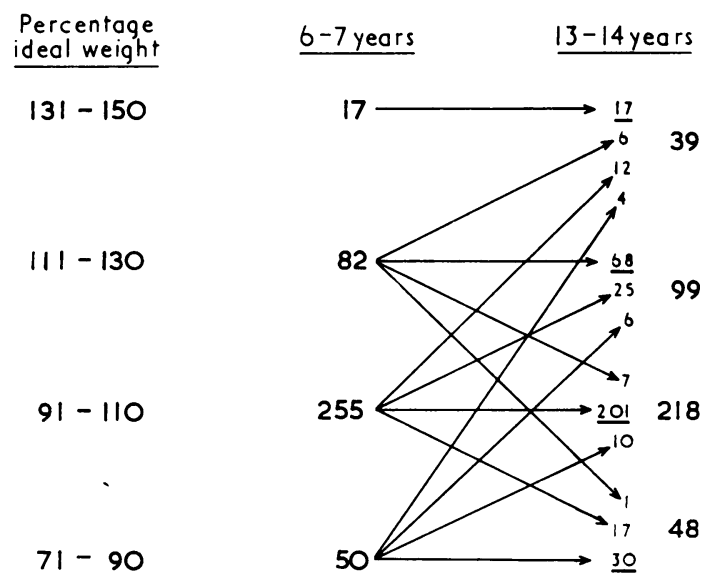

FIG. 2.-Relative weight changes according to weight groups at ages 6 to 7.

TABLE II

Distribution of relative weight at age 6 to 7 and shifts at age 13 to 14

\begin{tabular}{|c|c|c|c|c|c|c|c|}
\hline \multirow{3}{*}{$\%$ of ideal weight } & Age 6 to 7 & \multicolumn{6}{|c|}{ Age 13 to 14} \\
\hline & \multirow{2}{*}{ No. of children } & \multicolumn{2}{|c|}{ Unchanged } & \multicolumn{2}{|c|}{ Gain } & \multicolumn{2}{|c|}{ Loss } \\
\hline & & No. & $\%$ & No. & $\%$ & No. & $\%$ \\
\hline $\begin{array}{c}70-90 \\
91-110 \\
111-130 \\
131-150\end{array}$ & $\begin{array}{r}50 \\
255 \\
82 \\
17\end{array}$ & $\begin{array}{r}30 \\
201 \\
68 \\
17\end{array}$ & $\begin{array}{r}60 \\
79 \\
83 \\
100\end{array}$ & $\begin{array}{r}20 \\
37 \\
6 \\
-\end{array}$ & $\begin{array}{r}40 \cdot 0 \\
14 \cdot 5 \\
7 \cdot 3 \\
-\end{array}$ & $\begin{array}{r}-17 \\
8 \\
-\end{array}$ & $\begin{array}{l}- \\
6 \cdot 5 \\
9 \cdot 7 \\
-\end{array}$ \\
\hline Total & 404 & 316 & $78 \cdot 2$ & 63 & $15 \cdot 6$ & 25 & $6 \cdot 2$ \\
\hline
\end{tabular}


weight children of 13 to 14 years, 201 (93\%) had been of normal relative weight at age 6 to 7 ; the relative weight of only 10 children had been $90 \%$ or less (of ideal weight); and the relative weight of the 7 remaining children had been 110 to $120 \%$. Among the 48 children of 13 to 14 years whose relative weight was $90 \%$ or less, there was only one in whom it had been over $120 \%$ at age 6 to 7 .

The correlation coefficient of relative weight for the two age groups was 0.81 for the whole series, 0.80 for boys and 0.83 for girls. The regression lines are shown in Fig. 3. The standard

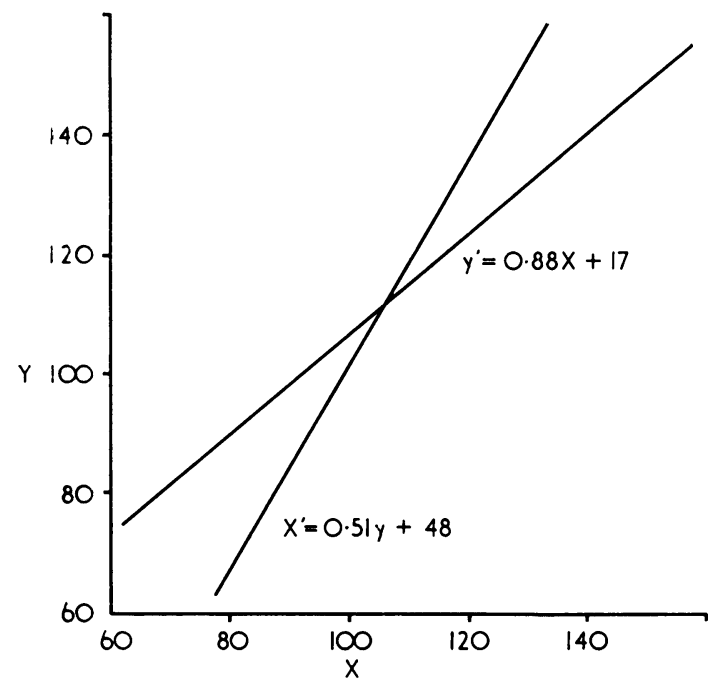

FIG. 3.-Linear regression lines for relative weight at both age groups. $y^{\prime}$ is prediction of relative weight at age 13 to $14(y)$ from relative weight at age 6 to $7(x) . x^{\prime}$ is prediction (retrospective) of relative weight at age 6 to 7 from relative weight at age 13 to 14 .

error of estimate is \pm 10 for prediction of $y$ from $x$ (relative weight at age 13 to 14 from relative weight at age 6 to 7 ) and \pm 8 for prediction of $x$ from $y$. When obese and nonobese children were considered separately, the correlation coefficients were 0.84 and 0.78 , respectively. The different $r$ values fell well within each other's confidence limits. All $\mathbf{r}$ values were highly significant ( $P$ $<0.001)$.

\section{Discussion}

The most significant finding of this study is the high degree of correlation for relative weight of each child between age 6 to 7 and age 13 to 14 . This positive correlation holds equally well for boys and girls, obese and nonobese children. Most children who had been obese at age 6 to 7 remained obese at the age of 13 to 14 ; children who showed an abnormally high relative weight at age 13 to 14 had been, in most instances, overweight already when 6 to 7 years old. Over a period of 7 to 8 years of rapid growth, a change of relative weight greater than $20 \%$ in either direction occurred in less than $6 \%$ of the children.

Other studies on obese children have drawn attention to the persistence of weight excess from early infancy to childhood (Eid, 1970; Asher, 1966) and from adolescence into early adult life (Mullins, 1958; Abraham and Nordsieck, 1960).

This long-term stability of relative weight has now been shown to exist not only in obese but in all children.

It may be concluded that the relative weight of both obese and nonobese subjects seems to be determined in early infancy and tends to remain constant during childhood, adolescence, and usually during adult life. This inherent stability of relative weight emphasizes the importance of genetic factors in determining body weight, as is born out in family studies (Mayer, 1965; Ellis and Tallerman, 1934), and in observations on identical twins (Newman, Freeman, and Holzinger, 1937; Shields, 1962). It is further corroborated by the poor long-term results of therapeutic attempts in obesity (Stunkard and McLaren-Hume, 1959; Glennon, 1966) and by the ultimate return to their original weight of most of those obese patients who succeeded in losing weight (Sohar and Sneh, 1973; Lloyd, Wolff, and Whelen, 1961 ; Alley et al., 1968).

In healthy children the term 'relative body weight' really indicates what percentage of body weight is made up of fat tissue. This implies that what remains constant throughout life is the amount (or percentage) of fat tissue in the body. It may well be that this is the genetically transmitted primary factor monitoring body weight.

\section{REFERENCES}

Abraham, S., and Nordsieck, M. (1960). Relationship of excess weight in children and adults. Public Health Reports, 75, 263.

Alley, R. A., Narduzzi, J. V., Robbins, T. J., Weir, T. F., Sabeth, G., and Danowski, T. S. (1968). Measuring success in the reduction of obesity in childhood. Clinical Pediatrics, 7, 112.

Asher, P. (1966). Fat babies and fat children. Prognosis of obesity in the very young. Archives of Disease in Childhood, 41, 672 .

Bruch, H., and Touraine, G. (1940). Obesity in childhood, family frame of obese children. Psychosomatic Medicine, 2, 141.

Eid, E. E. (1970). Follow-up study of physical growth of children who had excessive weight gain in first six months of life. British Medical fournal, $2,74$.

Ellis, R. W. B., and Tallerman, K. H. (1934). Obesity in childhood, a study of 50 cases. Lancet, $2,615$.

Glennon, J. A. (1966). Weight reduction-an enigma. Archives of Internal Medicine, 118, 1.

Lloyd, J. K., Wolff, O. H., and Whelen, W. S. (1961). Childhood obesity, a long-term study of height and weight. British Medical fournal, 2, 145. 
Mayer, J. (1965). Genetic factors in human obesity. Annals of the New York Academy of Sciences, 131, 412.

Mayer, J. (1966). Some aspects of the problem of regulation of food intake and obesity. New England fournal of Medicine, 274, 610, 662, and 722 .

Mendelson, M. (1966). Psychological aspects of obesity. International fournal of Psychiatry, 2, 599.

Mullins, A. G. (1958). The progress in juvenile obesity. Archives of Disease in Childhood, 33, 307.

Newman, H. H., Freeman, F. N., and Holzinger, K. J. (1937). Twins: A Study of Heredity and Environment. University of Chicago Press, Chicago.

Shields, J. (1962). Monozygotic Twins Brought Up Apart and Brought Up Together. Oxford University Press, London.
Sohar, E., and Sneh, E. (1973). Follow up of obese patients14 years after a successful reducing diet. (Submitted for publication.)

Stuart, H. C., and Meredith, H. V. (1969). Textbook of Pediatrics, 9th ed., p. 40. Ed. by W. E. Nelson, V. C. Vaughan, and R. J. McKay. Saunders, Philadelphia.

Stunkard, A., and McLaren-Hume, M. (1959). The results of treatment for obesity. Archives of Internal Medicine, 103, 79.

Correspondence to Dr. E. Sohar, Department of Medicine A, Heller Institute of Medical Research, Tel-Hashomer Hospital, Tel-Aviv, Israel.

The following articles will appear in future issues of this journal:

Annotation: Encephalopathy and fatty degeneration of viscera (Reye's syndrome). A. P. Mowat.

Measurement of serum parathyroid hormone, with particular reference to some infants with hypocalcaemia. A. Fairney, D. Jackson, and B. E. Clayton.

Wilson's disease or chronic copper poisoning? J. Walker-Smith and J. Blomfield.

Educational and social characteristics of children with asthma. R. G. Mitchell and B. Dawson.

Plasma glucagon levels in the term human infant and effect of hypoxia. $D$. I. Johnston and S. R. Bloom.

Effect of fatty acids on bilirubin conjugation. T. Hargreaves.

Personal practice: Intestinal biopsy in childhood. R. R. W. Townley and G. L. Barnes.

Acute anaphylaxis, pulmonary oedema, and intravascular haemolysis due to cryoprecipitate. D. Burman, $A$. $K$. Hodson, C. B. S. Wood, and N. F. W. Brueton.

Chronic lactic acidosis in association with myopathy. M. J. Tarlow, B. D. Lake, and J. K. Lloyd. 